\title{
A EXPERIÊNCIA Do "SÚbITo" NAS FICÇões de LISPECTOR E SARTRE
}

\author{
Eloísa Nogueira Aguiar ${ }^{\star}$
}

\begin{abstract}
Resumo
Trata-se da compreensão da experiência do "súbito" na psicoterapia existencial, como vivência fundamental ao processo de automovimento do cliente, através das literaturas de Lispector e de Sartre, as quais servem de fio condutor à explanação da eclosão do instante epifânico ou insight fulminante, onde o cliente, ao confrontarse com sua situação existencial, vê-se em estado iluminante e desconstrutor de seu modo peculiar de ver e entender as coisas. Nesse sentido a escolha ficcional desses escritores torna-se terapêutica, no sentido mais profundo que essa palavra possa ter, permitindo uma reordenação de nosso ser-no-mundo.

Palavras-chave: "Súbito". Psicoterapia existencial. Clarice Lispector. Jean-Paul Sartre.

\section{THE "SUDDEN'S" EXPERIENCE THROUGH THE Literature OF Lispector AND SARTre}

\begin{abstract}
The article approaches the experience of the "sudden" in the existential psychotherapy as a fundamental point in the client's process of self-movement. Such experience reveals the vast relation man-world and passes by Lispector's and Sartre's ideas which lead to the explanation of this epiphanic moment or fulminating insight when the client, facing his real existing situation, finds himself in a bright and disconstructing state of seeing and understanding tings. Far from everyday illusions, epiphany gives a new meaning to reality. Hence, the choice for this literature becomes therapeutic because it allows us a rearrangement of our being in the world.
\end{abstract}

Keywords: "Sudden”. Existential Psychotherapy. Clarice Lispector. Jean-Paul Sartre.

\footnotetext{
^ Professora do Curso de Psicologia da Universidade Estácio de Sá, Campus Resende. Mestre em Psicologia Clínica pela PUC-RJ e Doutora em Literatura Comparada pela UFF. Endereço: Rua D. Pedro I, 451/502, Liberdade, Resende, RJ.

E-mail: ea@bol.com.br
} 
"Mas enfim tenho que reconhecer que sou sujeito a essas transformações súbitas"

(SARTRE, 2000, p. 18).

A discussão pretende, através da intertextualidade, estabelecer relações de analogia (a qual pode se dar em vários sentidos: estrutura textual, nas ações, nos personagens, na trama dos fatos, nos cenários, objetos etc.) entre algumas obras de Clarice Lispector especificamente o romance A paixão segundo G. H. (1968) e o conto "Amor" (1960) e a novela A Náusea (1938) de Jean-Paul Sartre.

O desenvolvimento de certos temas importantes da ficção de Clarice Lispector (1920/1977) insere-se no contexto da filosofia da existência, formado por aquelas doutrinas que, muito embora diferindo nas suas conclusões, partem da mesma intuição kierkegaardiana do caráter pré-reflexivo, individual e dramático da existência humana, tratando de problemas como a angústia, o nada, o fracasso, a linguagem, a comunicação das consciências, alguns dos quais a filosofia tradicional ignorou ou deixou em segundo plano.

Assim como o filósofo existencialista francês Jean-Paul Sartre, Clarice Lispector explora a torturável ambigüidade da existência humana; o privilégio de ser gente e o absoluto confronto das liberdades e condições da particularidade de cada um.

Torna-se praticamente impossível não se associar a literatura introspectiva clariceana com o legado filosófico de Sartre (1905/1980), já que, para esse francês, a criação literária preludiava a criação filosófica, contendo as primeiras intuições, os conceitos em germe e as influências teóricas decisivas de que resultou, em 1943, seu tratado O Ser e o Nada (L'être et le néant), subintitulado Ensaio de Ontologia Fenomenológica (Essai d'Ontologie Phénoménologique), em cujo projeto começou a trabalhar em 1941, quando concluiu A Idade da Razão (L'âge de la raison), primeira das três novelas da série romanesca Os Caminhos da Liberdade (Les chemins de la liberté), ao lado de Sursis (Le sursis) e Com a Morte na Alma (La mort dans l'âme).

O esboço da filosofia de Sartre delineou-se em um romance, A Náusea (La nausée), origem de sua fama, iniciado em 1931 e concluído em 1937, e que narra as aventuras extraordinárias de Antoine Roquentin, em Bouville, pequena cidade francesa de província. Sem intriga, concentrado na descrição da vida interior do personagem, um historiador de profissão ali fixado com o intuito de escrever a biografia de certo marquês, o romance, moderno pela feição episódica da narrativa, desenvolve-se como um só monólogo, por meio de anotações de diário que registram o progresso de uma subjetividade em crise. Invadido pelo vulto extraordinário, obsessivo, que as coisas e as pessoas assumem aos olhos de Roquentin, circundadas por um halo de estranheza, a vida interior do personagem se desarticula, perdendo seu centro. É uma experiência avassaladora que culmina diante de um pé de castanheira do jardim público de Bouville. Antoine Roquentin olha a raiz da árvore e vê uma "massa negra e nodosa" que o ameaça, dentro de um jardim inóspito, viveiro de coisas inclassificáveis e inexplicáveis, que não se 
ajustam aos nomes que lhes damos; despidas do aspecto familiar com que nossos hábitos as revestem, cada qual se instala como realidade excessiva, bruta, nauseante, que engolfa a consciência. Mas daí surge a "súbita" iluminação reveladora da "existência", gratuita e injustificável.

Essa intuição da existência antecipa a filosofia de Sartre, baseada no método fenomenológico, assentado por Edmund Husserl (1859/1938): a descrição dos estados de consciência como atos vividos, com fundamento no caráter excêntrico da subjetividade, aproveitada nos registros psicológicos da crise de Roquentin. Enquanto escrevia $A$ Náusea, o romancista-filósofo travou contato com a Fenomenologia, que lhe inspirou a idéia de que os atos vividos possuem teor negativo ou "irrealizante", na medida em que a consciência distancia-se, como imaginação, dos dados momentâneos, transcendendo a realidade imediata.

Assim, pode-se vislumbrar nas literaturas de Sartre e de Lispector, a estranheza de um mundo indomesticado a quebrar as seguranças com as quais as personagens (como nós) tentam apoderar-se do cotidiano e que, subitamente, revelam o originário e, com ele, a angústia e a crise que possibilitarão o desguarnecer da fronteira entre o que é interior e o próprio universo. Vive-se, assim, a sagração do nada, o espanto que ele detona. Não se sabe como nem por que, mas a experiência desse acontecimento se realiza no próprio cotidiano, no momento em que a personagem (como nós) vê um cego mascando chiclete, a raiz de um castanheiro ou uma barata saindo do armário, enfim, num momento em que a personagem (como nós) está imersa em qualquer banalidade do cotidiano.

Assim, ao descobrir que o segredo da vida não está no aparente jogo do conforto da vida arrumada socialmente, mas no desconforto da visão do cego mascando chiclete, Ana, protagonista de "Amor" (LISPECTOR, 1960/1976), por exemplo, fornece ao leitor um caminho de descoberta, e o conto cumpre a tarefa literária de servir como operador de solução simbólica de conflitos existenciais. O mesmo se sucede com a experiência súbita de Roquentin, protagonista de A Náusea, onde tudo é "a mais" (de trop), ou seja, sem razão ou necessidade. Percebe que as características físicas dos objetos e as pessoas são somente fachadas reconfortantes para mascarar o nada da existência.

Clarice Lispector estréia no cenário literário brasileiro em 1944, com apenas 19 anos, com Perto do Coração Selvagem. Além desse romance, sua obra compõe-se de O Lustre (1946), A Cidade Sitiada (1949), A Maçã no Escuro (1961), A Paixão segundo G. H. (1964), Uma Aprendizagem ou o Livro dos Prazeres (1969a) e A Hora da Estrela (1977). Na área do conto, destacam-se as coletâneas Laços de Família (1960) onde está presente "Amor", A Legião Estrangeira (1964), Felicidade Clandestina (1971) e A Imitação da Rosa (1973). Além de romances e contos, Lispector é também autora de livros de crônicas (Visão de Esplendor, de 1975) e obras infantis (O Mistério do Coelhinho Pensante, de 1967, A Mulher que Matou os Peixes, de 1969b, e A Vida Íntima de Laura, de 1974).

Em suas obras, a introspecção que, ao pé da letra, quer dizer visão para dentro, parte da vida interior das personagens, levando a escritora a preocupar-se menos em desvendar-lhes o mecanismo psicológico dos atos que a própria razão 
metafísica do seu estar no mundo. A tomada de consciência por suas personagens obedece muitas vezes a um ritual reflexivo, tortuoso e, até mesmo, doloroso. É a partir daí que o "iluminado" se desprende dos laços convencionais da vida comunitária para viver, na nudez da autoconsciência, o seu drama existencial.

Partindo sempre de casos aparentemente banais (o leitor que lhe buscar apenas o enredo sairá certamente frustrado), a escritora se volta para esse mundo interior, dissecando a alma com a sua máquina de raios- $\mathrm{X}$, fazendo as personagens divagarem sobre o sentido de sua existência e sobre o estar-no-mundo. $\mathrm{O}$ resultado é extremamente angustiante: a existência humana não tem sentido. Só resta, então, uma solução-escolha: ou viver massificado, integrando-se nas estruturas e convenções que o mundo oferece, ou marginalizar-se. E é exatamente essa consciência do existir que estabelece essa dolorosa dualidade na inteireza do ser.

Assim, é de notar-se que a problematicidade da existência em face do universo, aflora em suas personagens, por via de um momento de iluminação intuitiva, por vezes através de um incidente aparentemente trivial, como a brusca freada a que sofrera o ônibus em que estava Ana, protagonista do conto "Amor":

[...] o bonde deu uma arrancada súbita jogando-a desprevenida para trás, o pesado saco de tricô despencou-se do colo, ruiu no chão, Ana deu um grito, o condutor deu ordem de parada antes de saber do que se tratava o bonde estacou, os passageiros olharam assustados. Incapaz de se mover para apanhar suas compras, Ana se aprumava pálida. Uma expressão de rosto, há muito não usada, ressurgia-lhe com dificuldade, ainda incerta, incompreensível (LISPECTOR, 1976, p. 29).

O momento epifânico a que se submetem seus personagens significa "revelação" e sempre de forma súbita, inesperada. Esse processo pode ser ativado (desencadeado) por qualquer fato banal do dia-a-dia: um beijo, um olhar, uma visão, algumas palavras, um susto. A partir desse momento (processo), a personagem, submersa num profundo fluxo de consciência, passa a ver o mundo e a si mesma de outro modo. Essa revelação introspectiva proporciona uma visão mais aprofundada da vida, das pessoas, das relações humanas etc.

Os momentos epifânicos, de modo geral, são traumáticos. Pois dão origem a rupturas de valores, questionamentos filosóficos e existenciais. Aproxima realidades opostas: nascimento e morte, bem e mal, amor e ódio, matar e morrer, seduzir e ser seduzido.

Tal como em Sartre, o assunto principal de Lispector em seu fazer literário é a consciência da personagem principal, que, sob um evento desencadeador a náusea experimenta uma longa e difícil avaliação de sua existência, até então resguardada, acomodada.

$\mathrm{Na}$ filosofia sartreana, a palavra náusea é usada para descrever o reconhecimento, pelo indivíduo, da contingência do Universo, de sua gratuidade e de seu absurdo. Roquentin, protagonista de $A$ Náusea compreende que esta vem do fato de que a existência precede a essência: o absurdo é o absoluto, já que 
toda a realidade é contingente, inclusive e principalmente ele mesmo. Tudo é "a mais" (de trop), ou seja, sem razão ou necessidade. Percebe que as características físicas dos objetos e as pessoas são somente fachadas reconfortantes para mascarar o nada da existência.

A vivência da náusea vai crescendo, vai cercando lentamente o atônito Roquentin. Há várias passagens que se assemelham a uma experiência mística, onde tudo continua o mesmo e ao mesmo tempo tudo mudou, sem palavras para precisar o ocorrido:

Nada mudou e, entretanto, tudo existe de outra maneira. Não posso descrever; é como a Náusea, e afinal é exatamente o contrário; enfim, sucede-me uma aventura e, quando me interrogo, vejo que me sucede que sou eu e que estou aqui (SARTRE, 2000, p. 72).

Assim como Roquentin, a personagem Ana de Lispector, também questiona o estar-no-mundo e o sentido da existência, focalizando a solidão do homem e sua angustiante dualidade entre uma existência autêntica ${ }^{1}$ ou inautêntica.

O espaço libertário que a ficção de ambos procura construir pressupõe a aventura que em termos de conhecimento ocorre na contínua (des) aprendizagem. E isso só é possível no corpo-a-corpo com a vida, tendo como principal agente desse processo o próprio indivíduo.

É a escritura que se faz no gerúndio, no "sendo" do Ser. É sobre o mistério de estar-no-mundo que ambos nos falam, o mistério de ser gente, G. H., Gênero Humano.

Suas histórias geralmente se iniciam com o personagem numa situação cotidiana. Aos poucos, prepara-se "algo", apenas pressentido, e, finalmente, esse "algo" ocorre, como uma iluminação que rouba o sentido habitual da realidade, revelando outro, totalmente "novo": "Esse momento foi extraordinário. Estava ali, imóvel e gelado, mergulhado num êxtase horrível. Mas, no próprio âmago desse êxtase, algo de novo acabava de surgir; eu compreendia a Náusea, possuía-a" (SARTRE, 2000, p. 193, grifo nosso).

E o sentimento da náusea coloca o homem/cliente, bloqueado e imerso em sua problemática, como o melhor intérprete de suas emoções, de sua realidade obstruída. E ele surge através de momentos de revelação epifânicos (momentos em que a realidade banal é percebida de forma encantatória e mágica, valorizando-se aspectos antes despercebidos do cotidiano e das coisas).

A epifania é, pois, uma manifestação existencial súbita, provocada por uma experiência que, a princípio, mostra-se simples e rotineira, mas acaba por mostrar a força de uma inusitada revelação. Os objetos mais simples, os gestos mais banais e as situações mais cotidianas provocam uma iluminação repentina na consciência dos personagens. Esse sentimento de angústia é a percepção, quer em surdina, quer em plena força, de que uma metamorfose abrupta de nosso projeto inicial é sempre possível. 
Tal situação é exposta declaradamente em "Amor" (LISPECTOR, 1960/1976), onde Ana, uma dona-de-casa "perfeita", cuidando bem do lar, do marido, dos seus filhos e vivendo para agradar os outros, esquece-se de si mesma. Num certo dia, em um bonde (quando voltava das compras), vê um cego mascando chiclete. Tal evento faz com que desperte e reflita sobre sua vida e sobre o mundo "momento epifânico". Ana agora completamente entregue ao mundo real depara-se com um cego diferente dos outros, que masca chiclete, detalhe que não permitia a si. O cego funciona como um espelho: vislumbra a sua cegueira diante do mundo o qual construíra, todo escuro, sem cor. Aos poucos, subitamente, algo começa a mudar em Ana: de repente, o bonde dá um solavanco e o embrulho de ovos que carregava cai, deixando sua sacola com um líquido pegajoso. Ana sai de sua casca, de sua frágil aparência e subitamente se depara com sua essência. Descontrolada, desce do bonde e depara-se com o Jardim Botânico, sem entender o que estava fazendo, pois muito havia passado do seu ponto de descida. Ana entra, senta e se envolve profundamente no seu desconhecido, onde tudo lhe parece estranho. Esta dona de casa, condicionada a um esquema tradicional da família burguesa dos anos 50, é tomada por uma onda de pensamentos que a levam a refletir sobre sua vida. No jardim, sente-se além, muito distante daquele mundo de exigências, horários, cobranças e regras que ela mesma criara, e nesse momento de inteira satisfação e entrega, deixa vir à tona a rotina de seus dias, ao mesmo tempo em que algo de inédito, diferente e "novo" lhe acontece; redescobre-se. O Jardim (leia-se mundo) é a contestação da identidade pessoal, do jogo dinâmico, muitas vezes tumultuado, de redescobrir a si e ao mundo. O jardim torna-se espaço de anulação da lógica cotidiana. Ao chegar a casa, acha este modo de ser cotidiano mais louco e irreal do que aquele em que acabara de estar no jardim.

Surge uma nova imagem; conseqüentemente, Ana não conseguiria mais ser a mesma. A partir do momento (processo) epifânico, a personagem, submersa num profundo fluxo de consciência, passa a ver o mundo e a si mesma de outro modo. Essa revelação introspectiva proporciona uma visão mais aprofundada da vida, das pessoas, das relações humanas etc. Os sentimentos e a capacidade de questionar tornam-se possibilidades de vida para aquela mulher "mascada" por uma rotina alienante. A epifania, momento súbito, rápido e não tomado pela palavra, leva Ana à lucidez, à clareza, a instantes de percepção, de brilho da inteligência, momentos perspicazes do uso da razão.

Tal como Ana, G. H. vive num mundo "quase", em que nada chega ao clímax. Tudo é medíocre. Também G. H. busca, em si mesma, pela introspecção radical, sua identidade e as razões de viver, sentir e amar. Ela está em seu apartamento tomando café, como faz todos os dias. Dirige-se ao quarto da empregada, que acabara de deixar o emprego. Lá vê "subitamente" uma barata, saindo de um armário. Este evento provoca-lhe uma náusea impressionante, mas, ao mesmo tempo, é o motivador de uma longa e difícil avaliação de sua própria existência, sempre resguardada, acomodada. A visão da barata é o seu momento de iluminação após o qual já não é a mesma, já não é a criatura alienada que tomava café distraidamente em seu apartamento. Nesse momento, deflagra-se na 
narradora a consciência da solidão (tanto dela, quanto da barata). Para regressar ao seu estado de um ser primitivo, selvagem -- e por isso mais feliz G. H. deve passar pela experiência de experimentar o gosto do inseto. Através da "provação" (que é a sua náusea física e existencial), estaria fazendo uma reviravolta em seu mundo condicionado e asséptico. A náusea, aqui tomada como "forma emocional violenta da angústia", é o momento que antecede a revelação, e a epifania resulta da dolorosa sensação da fragilidade da condição humana. A epifania constitui uma realidade complexa, perceptível aos sentidos, sobretudo aos olhos (visões), ouvidos (vozes) e até ao tato.

A personagem repensa toda a sua vida, o modo pelo qual se apresentou ao mundo, repensa o próprio Mundo e a existência. A angústia existencial perpassa todo o livro e, tal como em Sartre, há em Lispector uma afirmação da liberdade humana em meio ao absurdo da existência. "A angústia que, quando revelada, manifesta à nossa consciência a nossa liberdade, testemunha a modificabilidade perpétua do nosso projeto inicial" (SARTRE, 1997, p. 543). A modificação do projeto inicial é a todo o momento possível. A liberdade, segundo Sartre, é a possibilidade permanente daquela nulificação do mundo que é a própria estrutura da existência. "Estou condenado, a existir para sempre para além da minha essência, para além dos móbiles e dos motivos do meu ato: eu estou condenado a ser livre" (SARTRE, 1997, p. 516). Isto significa que não se podem encontrar para a minha liberdade outros limites além da própria liberdade: ou, que não somos livres de deixar de ser livres. A liberdade não é o arbítrio ou o capricho momentâneo do indivíduo: radica na mais intima estrutura da existência, é a própria existência.

Assim, ao comer a barata, G. H. afirma plenamente sua liberdade perante as normas sociais interiorizadas e perante o Nada. Seu inferno está justamente em inserir-se profundamente no mistério da existência, na reflexão sobre si mesma e sobre a vida em geral, buscando um sentido universal nessa sua experiência com a figura abjeta de uma barata. Em suma, ela busca o sentido do não-sentido. Não há fronteiras nítidas entre o Eu e o Não-Eu, entre a parte e o todo. "É que eu olhara a barata viva e nela descobria a identidade de minha vida mais profunda" (LISPECTOR, 1968, p. 67). Ao comer o inseto, G. H. realiza a fusão do seu Eu com o ser da barata. Inicia uma jornada rumo a uma experiência de integração entre o Eu e o mundo, entre o ser-para-si e o ser-em-si.

O ser sartriano se desdobra em duas dimensões: o ser-em-si e o ser-para-si. O ser-em-si, o fenômeno, opaco para si mesmo, simplesmente é, caracterizandose como uma realidade marcada pelo absurdo, pelo fechamento sobre si mesmo. O ser do fenômeno é posto pela consciência, o ser-para-si, definido "como sendo aquilo que não é e não sendo aquilo que ele é" (SARTRE, 1997, p. 39). Para Sartre, a consciência é uma fissura dentro do ser: por ela irrompe o nada no mundo. Através dessa fissura, o ser-para-si pode ultrapassar suas barreiras, caracterizando-se como possibilidade de transcendência do limite, como espontaneidade criadora. As duas dimensões do ser convivem no tempo e constituem a existência humana. A perspectiva de Sartre é materialista, portanto a consciência, por seu caráter intencional, de relação com o mundo, se identifica com o corpo. Devido à 
sua conotação corporal, o ser-para-si se caracteriza como ação e, portanto como liberdade. O que caracteriza o ser-para-si é a capacidade de fazer-se. O homem não é "aquilo que é", ele se faz.

Assim, ao perder o seu Eu, G. H. encontra o "eu ser”, a existência pura, que provém "de uma fonte muito anterior à humana e, com horror, muito maior que a humana" (LISPECTOR, 1968, p. 74). Sem o seu eu mundano, coisificado, G. H. entra e se dilui no mar da existência.

A literatura de Clarice tem esta mesma potência geradora de realidades invisíveis, permitindo a nossa visão de aspectos insuspeitos de nós mesmos. Atua, assim, como o psicólogo com seu cliente, o vislumbre do que até então era pura invisibilidade. Permite uma reordenação de nosso ser-no-mundo, uma busca violenta da aprendizagem do ser, enfim, coloca-nos em contato com o óbvio, que é a verdade mais difícil de ser enxergada. Podemos dizer, então, que a proposta ficcional de Lispector e de Sartre é de busca, de um encontrar-se reiterado com nossa própria existência, de um entregar-se à percepção do fantástico presente na vida a mais cotidiana, que nós, temendo a dor desta vertigem, procuramos negar.

Assim, suas narrativas dão forma à filosofia, ou à vida, pois, o que é realizado, o que toma forma e enseja, é o estar-no-mundo a epifania, esta revelação imediata do mundo, um estar imerso e ser feito do mesmo tecido das coisas. Mas, este estado - de graça, ou crise, como o chamou Lispector - não se conforma nas regras de decodificação em que se ampara nosso pensamento, que tem como coordenadas o tempo e o espaço e que supõe que o mundo se apresenta como coisa natural a nós destinada.

A experiência a que nos condena Lispector e Sartre em sua força de literatura é a de um desnudamento de nosso olhar anterior, uma surpresa frente ao desconhecimento que mantínhamos, um assombro frente à negação de nossas próprias forças geradoras, um susto por não termos percebido antes o quanto deixávamos de ver. Proporciona-nos o súbito, onde as coisas são vistas sendo: com um Eu que ama, fala, organiza, que nos dá algo mais, nos fazendo também ser. Desta forma, a experiência de G. H. e de Roquentin torna-se uma das mais audaciosas viagens do ser em busca da matéria-prima de sua humanidade.

Desta forma, a descoberta do Ser demonstra, simultaneamente, o Não-Ser, que ocupa a maior parte da vida do indivíduo, pois o cotidiano é um véu posto na face da existência. Na epifania, o cotidiano é visto como pobreza de vida, levando o indivíduo a uma nova forma de encarar o viver, atrevendo-se a rasgar a "casca" do cotidiano (o ovo que cai em "Amor" [LISPECTOR, 1960/1976]). Também G. H. depara-se com a existência sem as amarras do eu-social e adquire uma amplitude no modo de encarar as coisas.

Daí a importância da barata na narrativa clariceana. O confronto com esse inseto marca o início de uma ruptura não apenas com a maneira de viver, mas com a engrenagem com o sistema geral dos hábitos mundanos (NUNES, 1989). 
Diante do desmoronamento do eu-social e toda a carga de atributos e valores que este sustenta a noção de beleza, não só entra em crise, como cai por terra. $\mathrm{O}$ mundo de G. H. era pautado na suposição da beleza como valor social. A elegância de seu apartamento, suas esculturas e a idéia de limpar o quarto da empregada estão ligadas à visão estética sustentada pela personagem. Diante do confronto com o grotesco, que a barata representa, o conceito de belo social é anulado, levando-a a reconhecer que perdeu o medo do feio (LISPECTOR, 1968).

A existência em estado bruto permanece intocável nos animais, apesar da domesticação, ao contrário do homem que se anula diante da civilização. Os animais não precisam abrir mão de sua essência em detrimento de uma convivência social. Eles habitam a terra como são, sem mascaramentos. Assim, pela epifania, o próprio homem estranha o que é humano, fazendo com que a consciência do ser torne-se presa fácil da náusea. E, como nos diz Nunes, "tanto em Sartre quanto em Lispector, a náusea é o ponto de ruptura do sujeito com a praticidade diária" (NUNES, 1989, p. 121). Somente uma experiência de força, como a náusea, é que pode mostrar ao indivíduo uma visão ilimitada das possibilidades de sua vida. Sofrer a náusea é doloroso, mas é necessário como única forma de destruir aquilo que impede a manifestação da verdade existencial.

Sant'Anna fala explicitamente da epifania, conceituando-a como uma súbita revelação da verdade (SANT'ANNA, 1988, p. 5). Mas que verdade é esta? A do ser e de sua existência. Também Bosi cita o caráter revelador de uma verdade na epifania (ou insight fulminante), em que há o alargamento de horizontes, levando a pessoa a ver a realidade de uma outra maneira. Assim, a epifania, em seu dizer, despoja o "eu" das ilusões cotidianas e o entrega a um novo sentido da realidade (BOSI, 1995). Essa iluminação que vai se dando aos poucos e subitamente eclode na consciência fazendo-nos questionar nossa inserção passiva na cotidianidade e colocando-nos diante de nossa liberdade de autocriação é belamente descrita por Sartre em sua novela $A$ Náusea, ${ }^{2}$ na pele do protagonista Roquentin.

Antoine Roquentin é um intelectual pequeno-burguês, solitário, sem amigos, sem raízes, vivendo numa pensão na província de Bouville, onde se dedica a escrever a biografia de certo senhor Rollebon, aventureiro que teria vivido no século XVIII. Sua vida se resume a freqüentar um Café e a pesquisar na biblioteca pública da cidade. Fora isso, tudo mais lhe parece sem interesse: as pessoas, as coisas, ele mesmo. Apropriadamente, Sartre dá a esta novela uma epígrafe, que define a situação do protagonista: "É um rapaz sem importância coletiva; é apenas um indivíduo".

Instalado na monotonia de sua existência, certo dia, sentado no banco de um jardim público (lembremos de Ana no conto "Amor" [LISPECTOR, 1960/1976]), sente, subitamente, uma "iluminação" que lhe revela a gratuidade, a contingência, a absurdidade da própria existência. A realidade do mundo, do jardim, do banco, do castanheiro cuja raiz mergulha na terra sob o banco, do próprio Roquentin, reduzia-se simplesmente a um "estar-aí" gratuito, absurdo, carecedor de sentido, sem por que, sem para quê. 
O essencial é a contingência. $O$ que quero dizer é que, por definição, a existência não é a necessidade. Existir é simplesmente estar presente [...] A contingência não é uma ilusão, uma aparência que se pode dissipar; é o absoluto, por conseguinte a gratuidade perfeita. Tudo é gratuito: esse jardim, essa cidade e eu próprio (SARTRE, 2000, p. 193-194).

E, mergulhado num "êxtase horrível”, compreende a náusea, a possui; ele e ela são uma só coisa. Em Roquentin, opera-se uma transição que corresponde às etapas pelas quais:

(1) o homem entra em contato com o mundo dos objetos e simplesmente os utiliza (ausência da náusea); (2) percebe o caráter ameaçador dos objetos. Antes deste instante-já não pressentira o significado de "existir": "de repente, ali estava, claro como o dia: a existência subitamente se revelara. Perdera seu aspecto inofensivo de categoria abstrata..." (SARTRE, 2000, p. 188).

A conseqüência da náusea é a responsabilidade que devemos constatar em nós pelo simples fato de existirmos; é um abraço no mundo do mundo que pesa "intensamente sobre nosso coração como um grande animal imóvel" (SARTRE, 2000, p. 195).

A experiência, portanto, de resgate do existir autônomo, recorrente nas obras literárias de Lispector e de Sartre, afina-se com a proposta terapêutica existencial, na qual o cliente é convidado a revisitar sua situação no mundo, buscando na auto-expressão autêntica o compromisso do indivíduo consigo mesmo, o sentimento de responsabilidade pela própria existência e a liberdade para o indivíduo fazer as suas próprias escolhas, descobrindo quem de fato ele é e construindo quem ele quer ser. Afinal, a preocupação básica da fenomenologia é a de contribuir para a superação do senso comum (atitude natural), para que os indivíduos possam assumir uma postura fundamentada e crítica (atitude fenomenológica), tal como sucede com os personagens de ambos na vivência da epifania crítica, onde a realidade revelada mostra a real condição de anulação do ser em seu cotidiano amorfo, causando-lhe um mal-estar súbito, porém iluminante, dado o poder de ruptura da náusea, que abre caminho para o novo, para descobertas, para a confrontação com o que achamos necessário (fundamental) para nós:

Perdi alguma coisa que me era essencial, e já não me é mais. Não me é necessária, assim como se eu tivesse perdido uma terceira perna que até então me impossibilitava de andar, mas que fazia de mim um tripé estável. Essa terceira perna eu perdi. E voltei a ser uma pessoa que nunca fui (LISPECTOR, 1968, p. 8).

A metáfora da "terceira perna" explica a função do eu-social como obstáculo à descoberta da verdade do ser. Antes da experiência epifânica com a barata, G. H. julgava essencial aquela peça inútil. Como nos diz Nunes (1989), o con- 
fronto com o inseto marca o início de uma ruptura não apenas com o cotidiano da personagem, mas com a engrenagem com o sistema geral dos hábitos mundanos. Vejamos mais um trecho da obra:

Ontem, no entanto, perdi durante horas e horas a minha montagem humana. Se tiver coragem, eu me deixarei continuar perdida. Mas tenho medo do que é novo e tenho medo de viver o que não entendo quero sempre ter a garantia de pelo menos estar pensando que entendo, não sei me entregar à desorientação. Como é que se explica que o meu maior medo seja exatamente o de ir vivendo o que for sendo? Como é que se explica que eu não tolere ver, só porque a vida não é o que eu pensava e sim outra - como se antes eu tivesse sabido o que era! Por que é que ver é uma tal desorganização? E uma desilusão. ${ }^{3}[\ldots]$ Talvez desilusão seja o medo de não pertencer mais a um sistema (LISPECTOR, 1968, p. 9-10).

Assim, é preciso atuar junto ao cliente de forma a buscar o que lhe é mais próprio, clarificando a forma como abre mão de sua liberdade. O processo psicoterapêutico vai se dar, então, de forma a restabelecer a relação do "eu" consigo próprio e, ao mesmo tempo, a relação desta relação com o mundo. Trata-se de resgatar a fluidez que constitui o "eu", nas relações eu-eu, eu-eu-mundo, eu-mundo.

Tal qual o psicólogo existencial com seu cliente, a literatura intimista de ambos os autores aqui estudados possibilita o cara-a-cara com a inautenticidade, permitindo, então, ao cliente/leitor uma reordenação de seu ser-no-mundo. Ambos não curam dores e doenças, não dissimulam conflitos, nem amenizam a busca de ser, mas, pelo contrário, por não amortecerem nossas loucuras, por não amenizarem nosso estranhamento frente ao mundo e a nós mesmos, nos levam à compreensão de que a aprendizagem se realiza através de momentos súbitos, violentos, mas iluminantes.

É nesse sentido que a atuação clínica existencial deve se operar, mantendo a angústia frente àquilo que sustenta a questão, não facilitando a fuga para o impessoal, não afastando o cliente de seu ser mais próprio. Afinal, como diz existencialmente Lispector, na pele de G. H., "é em mim que tenho de criar esse alguém que entenderá" (LISPECTOR, 1968, p.51).

Essas considerações apontam a inter-relação de seus escritos com a psicoterapia existencial, a qual postula que cabe ao indivíduo/cliente mesmo atado a uma existência inautêntica, artificial, a decifração de sua vida, a qual o coloca frente a frente com o exercício de sua liberdade. Tal experiência de autoconhecimento só se dá na abertura ao mundo, na saída do mundo próprio (da organização que se dava aos fatos da vida) para o mundo da vida (caos informe, desconhecido), na transmutação de uma personalidade reificada para a construção de uma identidade mais autêntica. E a eclosão da necessária "iluminação" dá-se subitamente, através de uma singular vivência experimentada na comunhão com o mundo. 
Na clínica, o sentir-se "esquisito" de muitos clientes nos comunica um sentimento de profunda solidão e a necessidade de pertencer à espécie humana, à vida e ao tempo presente. Tal como experimentam os personagens de Lispector e de Sartre com os demais entes; é na relação intersubjetiva com o psicoterapeuta que se anuncia a experiência inédita do "pertencer": "Pertencer é viver" (LISPECTOR, 1994, p. 111).

A obra literária de Lispector e de Sartre é, assim, terapêutica, e terapêutica no sentido mais profundo que esta palavra possa ter, pois a atenção concedida por eles, permite-nos uma reordenação de nosso ser no mundo. É, assim, transfiguradora, mas não por nos curar de nossas dores e de nossas doenças, não por dissimular nossos conflitos, não por amenizar nossa busca de ser. Não. Ela não amortece nossas loucuras, ela não ameniza nosso estranhamento frente ao mundo e a nós mesmos; muito pelo contrário, faz-nos olhar no olho de nossas entranhas, na busca violenta da aprendizagem do ser.

Portanto, não há um porão secreto, não há uma verdade escondida a ser desenterrada através dos instrumentais perfuradores de nosso intelecto. A proposta literária de ambos é de uma busca, ou melhor, de um encontrar-se reiterado com nossa própria existência, de um entregar-se à percepção do fantástico presente na vida a mais cotidiana, que nós, temendo a dor desta vertigem, procuramos negar.

Se a precaução de Ana, no conto "Amor" reduz-se:

[...] a tomar cuidado na hora perigosa da tarde, quando a casa estava vazia sem precisar mais dela, o sol alto, cada membro da família distribuído nas suas funções. Olhando os móveis limpos, seu coração apertava um pouco em espanto. Mas na sua vida não havia lugar para que sentisse ternura pelo seu espanto (LISPECTOR, 1976, p. 28).

Clarice Lispector pede de nós esta ternura pelo espanto, um estado de prolongado nascimento, onde a fluidez entre eu e mundo possa sempre se dar. "Desejava ainda mais: renascer sempre, cortar tudo o que aprendera, o que vira, e inaugurar-se num terreno novo onde todo pequeno ato tivesse um significado, onde o ar fosse respirado como da primeira vez" (LISPECTOR, 1998b, 77).

\section{Notas}

\footnotetext{
${ }^{1}$ A expressão autenticidade na filosofia existencial denota o modo de ser do homem que se funda numa consciência autônoma. Em um sentido amplo, de acordo com Olson, "a vida autêntica é a que se baseia numa apreciação exata da condição humana [...] A inautenticidade, por outro lado, é uma existência cotidiana que estaria distante das responsabilidades pessoais, levada pela mediocridade das massas" (OLSON, 1970, p. 166).

${ }^{2}$ A náusea é uma expressão literária da antiga teoria sartreana da contingência, que vinha desenvolvendo desde "A Legenda da Verdade", seu primeiro livro, escrito em 1931 - conto destinado a veicular suas idéias filosóficas, tal como se repete em $A$ Náusea.

${ }^{3}$ Desiludir-se aqui significa sair da ilusão em que se encontra em relação ao mundo, ou melhor, o mundo é construído por ilusões que precisam ser desfeitas para que se atinja a verdade. Lembremos que para Kierkegaard a "verdade" é subjetividade.
} 


\section{REFERÊNCIAS}

BOSI, A. Clarice Lispector. In: História concisa da literatura brasileira. São Paulo: Cultrix, 1995.

LISPECTOR, C. A descoberta do mundo. Rio de Janeiro: F. Alves, 1994. . A legião estrangeira (1964). São Paulo: Ática, 1988.

. O Lustre. Rio de Janeiro: Agir, 1946.

. A cidade sitiada. Rio de Janeiro: A Noite, 1949.

. A Maçã no Escuro. Rio de Janeiro: F. Alves, 1961.

. O Mistério do Coelhinho Pensante. [S.1.: s.n.], 1967.

. Uma Aprendizagem ou O Livro dos Prazeres. Rio de Janeiro: Sabiá, 1969a. . A Mulher que Matou os Peixes. [S.1.: s.n.], 1969b

. Felicidade Clandestina. Rio de Janeiro: Sabiá, 1971.

. A Imitação da Rosa. Rio de Janeiro: Artenova, 1973.

. A Vida Íntima de Laura. [S.1.: s.n.], 1974.

. Visão de Esplendor: impressões leves. Rio de Janeiro: F. Alves, 1975.

. Amor (1960). In: Seleta. Rio de Janeiro: J. Olympio, 1976. p. 27-36.

. A Hora da Estrela. Rio de Janeiro: J. Olympio, 1977.

. A paixão segundo G. H. (1964). Rio de Janeiro: Sabiá, 1968.

. Laços de família (1960). Rio de Janeiro: Rocco, 1998a.

Perto do coração selvagem (1944). Rio de Janeiro: Rocco, 1998 b.

NUNES, B. O drama da linguagem: uma leitura de Clarice Lispector. São Paulo: Ática, 1989.

OLSON, R. G. Introdução ao existencialismo. São Paulo: Brasiliense, 1970.

SANT'ANNA, A. R. Clarice: a epifania da escrita (prefácio). In: LISPECTOR, C. A legião estrangeira. São Paulo: Ática, 1988. 
SARTRE, J. P. A náusea. 10. ed. Rio de Janeiro: Nova Fronteira, 2000. Vozes, 1997.

O ser e o nada: ensaio de ontologia fenomenológica. Petrópolis, RJ, . A idade da razão (Os caminhos da liberdade, v. 1). Tradução Sérgio Milliet. São Paulo: Abril Cultural, 1972.

. Sursis (Os caminhos da liberdade, v. 2). Tradução Sérgio Milliet. São Paulo: Círculo do Livro, 1978.

. Com a morte na alma (Os caminhos da liberdade, v. 3). Tradução: Sérgio Milliet. Rio de Janeiro: Nova Fronteira, 1983.

Recebido em: outubro de 2005

Aceito em: abril de 2006 